\section{EMBRYRIDDLE}

Aeronautical University

SCHOLARLY COMMONS
Journal of Aviation/Aerospace

Education \& Research

Volume 12

Number 2 JAAER Winter 2003

Article 2

Winter 2003

\title{
A Case for Changing the National Airspace System from a \\ Magnetic North to a Geographic North Based Model
}

Michael K. Larson

Follow this and additional works at: https://commons.erau.edu/jaaer

\section{Scholarly Commons Citation}

Larson, M. K. (2003). A Case for Changing the National Airspace System from a Magnetic North to a Geographic North Based Model. Journal of Aviation/Aerospace Education \& Research, 12(2).

https://doi.org/10.15394/jaaer.2003.1579

This Article is brought to you for free and open access by the Journals at Scholarly Commons. It has been accepted for inclusion in Journal of Aviation/Aerospace Education \& Research by an authorized administrator of Scholarly Commons. For more information, please contact commons@erau.edu. 


\title{
A CASE FOR CHANGING THE NATIONAL AIRSPACE SYSTEM FROM A MAGNETIC NORTH TO A GEOGRAPHIC NORTH BASED MODEL
}

\author{
Michael K. Larson
}

\begin{abstract}
The Global Positioning System (GPS) is currently playing a major role in aviation navigation and is proposed by the Federal Aviation Administration (FAA) to be the foundation of the future National Airspace System (NAS). The Position, Velocity and Time (PVT) information provided by GPS for navigation purposes is directly based on Geographic North parameters rather than on Magnetic North, which is currently the foundation of the NAS. This paper uniquely addresses the exploration of this relationship between the GPS and Geographic North by applying an experimental research design to analyze the potential benefit of basing the NAS on Geographic North. This study proposes to quantify the benefits of a Geographic North Model by comparing the performance of navigation tasks by university flight students using a Geographic North model versus those using a Magnetic North model. Similar treatments, consisting of navigational training relating to Geographic North for the experimental group and Magnetic North for the control group, were administered to both groups. Identical navigational tasks were then presented to both groups to perform, using their respective models, and data was collected for the dependant variables of accuracy and time of task performance. The statistical tools of Chi-square and two-tail t-tests with alpha of .05 were applied to the data to evaluate the hypothesis that accuracy and time would both improve with the Geographic North model. The Geographic North group did outperform the Magnetic North group for each dependant variable, but the results were found to be statistically significant for only the time-of-task variable.
\end{abstract}

\section{RATIONALE FOR CHANGING THE NAVIGATION MODEL}

The dramatic acceleration of technology is having a significant impact on aviation as we begin the 21 st century. Aviation technology is advancing so rapidly that keeping pace with the changes is becoming problematic for the pilots who operate in the system. One of the most noteworthy changes is the replacement of the current Very High Frequency Omnidirectional Range (VOR) based National Airspace System (NAS) with the Global Positioning System (GPS). GPS is a satellite-based navigation system, using satellites to provide properly equipped users with highly accurate position, velocity, and time (PVT) information (FAA satellite navigation program master olan. 1993). The system, which is controlled and operated by the Department of Defense (DOD), currently provides worldwide navigation capability to both the military and civilian segments of aviation (The global positioning system, 1995). Until May 1,2000 , the DOD allowed only selective availability (SA) to the civilian users. Essentially, selective availability provided a GPS signal, which was deliberately degraded by the DOD for national defense purposes. The DOD now has the capability to degrade or eliminate the use of GPS in designated areas throughout the world and, therefore, has determined that it is no longer necessary for national security to degrade the GPS signal to non-military users (GPS fluctuation, 2000). Therefore, all GPS users now have nearly unlimited access to the full precision capability of the Global Positioning System.

GPS is proposed by the Federal Aviation Administration (FAA) to be the primary radio navigation system for the NAS in the early 21 st century (Federal Radio Navigation Plan, 1999). The current Federal Radionavigation Plan (FRP) projects that a phase-down will begin in 2008 for most of our currently used land- 
based radio navigation facilities. The current ground-based systems will either be phased out completely or remain in a lesser supportive role. In some of the more remote areas such as Alaska, the GPS is already being widely used because ground-based facilities are either unavailable or unreliable. A trial program is currently being tested and studied in the Alaska bush country to determine its validity and reliability for navigating, communicating, and collision avoidance (Capstone Program, 2000). This major transition from ground-based navigation to GPS is rapidly gaining momentum while the number of pilots being trained to utilize the new system is remaining relatively stagnant. There is a very real danger of this new technology outrunning the existing capabilities of the very people the system is designed to help.

The capabilities of GPS render some of our former navigational concepts and procedures unnecessarily cumbersome and antiquated. Current GPS technology affords the accuracy and simplicity of operation to provide the aviation community with a system as easy to operate as the computerized video games with which the youth of our world are already intimately familiar. The aviation community must begin to think creatively and futuristically to take advantage of the incredible capabilities of GPS. Government, industry, educational institutions, and private enterprises need to aggressively pursue research in the fields of flight simulators, advanced displays, flight deck ergonomics, automation, human/machine interfacing, human factors, and many other vital issues associated with the new capabilities and technologies becoming available (Williams, 1999).

One area of study meriting attention relates to the enhanced usability and simplification of the present basic navigation model, which currently uses Magnetic North as its paradigm. The GPS makes the use of Magnetic North unnecessary and, indeed, undesirable. GPS automatically determines position with respect to Longitude and Latitude and motion with respect to True (Geographic North) along a Great Circle Route (the shortest distance between two points on the Earth's surface)(Bowditch, 1981). In fact, most current aviation GPS receivers provide navigational information via moving map or Horizontal Situation Indicator (HSI) displays, which automatically and instantaneously provide the True Flight Track (TFT) of the aircraft with respect to Geographic North.

The cumbersome procedures of converting True Courses to Magnetic Headings by applying corrections for
Wind Correction Angles, Magnetic Variation, Magnetic Deviation, and Magnetic Disturbances are no longer required for either efficacy or safety of flight. Other advantages to Geographic North include: (1) Winds Aloft Forecasts are given relative to True North. (2) FAA Air Traffic Controllers (ATC) currently provide radar traffic advisory information and aircraft radar vectors relative to the True Flight Track (TFT) of the aircraft (Nolan, 1994), and (3) the constant shifting of the Magnetic North Pole will no longer be a factor (especially important as precise GPS instrument approach procedures become more prevalent).

Magnetic North orientation devices (for example, the magnetic compass) will continue to have value as a backup system and a method to assist the pilot(s) in determining the aircraft's heading (longitudinal axis) relative to the ground. However, Magnetic North should no longer be the primary paradigm upon which aviation bases its navigation procedures. The entire aviation system would greatly benefit from the straightforward and simplified approach which a Geographic North based navigation system offers.

The question, then, is whether the use of a Geographic North Model will enhance pilots' ability to perform navigation tasks and, thus, ultimately improve the efficacy and safety of flight. The answer to this question becomes the primary focus of this study, which is to test the hypothesis that flight students performing navigation tasks based on a Geographic North Model will do so more accurately and more expeditiously than those students using the traditional Magnetic North Model.

\section{EXPERIMENTAL RESEARCH DESIGN MODEL}

The purpose of this study is to determine if the performance of navigation tasks by flight students using a Geographic North Model exceeds that of those students using the traditional Magnetic North Model. A quasiexperimental methodology using the nonequivalent control group design (Salkind, 1997) is used to compare the effect of the two levels of the independent variable (Geographic North versus Magnetic North based model) on the dependent variables (accuracy and expediency of performing navigation tasks) for the two subject groups observed in this study. The procedures used included: (a) selecting the population sample, (b) administering a prestudy survey and a pretest to help verify homogeneity within and between the two study groups, (c) conducting a post-study survey to help verify homogeneity between the two instructional presentations, (d) creating a lesson plan 
for each presentation (that is, geographic north versus magnetic north), and (e) analyzing the data collected using $t$ tests for interval scale data and Chi-square tests for nominal scale data.

The study was based on the presentation of two instructional lessons to the two groups (Appendixes A \& B). The experimental group received instruction to perform navigation tasks based on the use of a geographic north model. The control group received instruction to perform navigation tasks based on the use of a Magnetic North Model. The instruction was administered to both subject groups in the same classroom and during the regularly scheduled class periods for each section. The two study groups met at different times on different days. Surveys were administered to both groups before and after the study to assess the homogeneity of the two groups and the consistency of the instructional environment.

Lesson plans were developed by the researcher based on his background and experience as a FAA Certified Flight Instructor (Gold Seal, Airplane Single and Multiengine Instrument Airplane) and as a FAA Designated Pilot Examiner and the following resources:

1. FAA Designated Pilot Examiner's Handbook

2. FAA Aviation Instructor's Handbook

3. FAA Flight Training Handbook

4. FAA Practical Test Standards

\section{Pilotage and Dead Reckoning}

The lesson plans were constructed to consider two elements of planning a cross-country flight: pilotage and dead reckoning. Pilotage is the technique of navigation from one point to another by comparing what is visually observed in flight to the cartographic information depicted on an aeronautical chart along the course plotted by the pilot. Dead reckoning is the technique of pre-calculating the navigation from one point to another by using existing information including the direction and distance of the route to be flown, aircraft performance values, wind direction and speed, and other variables. Pilots flying using Visual Flight Rules (VFR) are advised to use both pilotage and dead reckoning techniques when preparing for and navigating on a cross-country flight (Private Pilot Manual, 1997).

\section{Magnetic North Model}

The magnetic north model lesson plan was developed to follow the traditional format of navigation by using magnetic heading $\mathrm{MHD}$. the magnetic compass and the gyroscopic heading indicator as the primary guidance systems. Magnetic heading is calculated from the true course (TC) plotted on the aeronautical chart for the cross- country flight by adjusting for the wind correction angle (WCA) and magnetic variation. Magnetic deviation was not included in the evaluation of the subjects' performance. Wind correction angle, ground speed, and fuel consumption are calculated in the traditional fashion using the E6-B flight computer (Private Pilot Manual, 1997).

\section{Geopraphic North Model}

The Geographic North Model lesson plan was developed to be similar to the traditional magnetic north based instruction with the exception that the determination of a magnetic heading (MH) is not required because the GPS navigation display automatically depicts the true flight track (TFT) of the aircraft as the primary guidance format without regard to wind correction angle, magnetic variation, or magnetic deviation. The TFT information is displayed on the GPS receiver via alphanumeric data, moving map display, a simulated horizontal situation indicator (HSI), or a combination of the three. TFT is equivalent to the Great Circle Route (GCR) of the flight and is nearly identical to the true course plotted on the aeronautical chart (Lambert Conformal Conical format) (Private Pilot Manual, 1997).

The E6-B is still used to calculate wind correction angle and ground speed for enroute time and fuel use calculations. The wind correction angle, while not needed for course guidance with this model, will still be included in this exercise to determine the relationship between the heading of the aircraft and the TFT. Pilots need this information to maintain a general orientation of their aircraft's longitudinal axis to the earth's surface.

\section{DEVELOPMENT OF MEASUREMENT INSTRUMENTS}

Three instruments were used in this study to measure the performance of the subjects in each study group. The first instruments were the pre- and post-study surveys (Appendixes C \& D). The pre-study survey posed questions through which the subjects could rank their experience and knowledge levels. This was designed to be an indicator of the homogeneity within each group and between the two separate study groups. The post-study survey posed questions through which the subjects could rank the understandability and difficulty levels of the navigational information presented and the navigational devices (sectional chart, plotter, and E6-B) used to perform the tasks presented to them. This was designed to be an indicator of the consistency between the two different treatments.

The second instrument was the Pre-test (Appendixes C \& D), which consisted of a navigational task, which was identical for both groups. The Pre-test was 
designed to measure the subject's knowledge and skill level in performing the navigational computer (E6-B) portion of navigation task for cross-country flight. Two parameters were measured: the accuracy of the computations performed by the subject and the amount of time needed to accomplish the task.

The third instrument was the Post-test (Appendixes C \& D), which consisted of a cross-country navigational problem and an emergency deviation to the nearest airport problem. The navigation problems were the same with the exception that the experimental group based their measurements and calculations on Geographic North parameters whereas the control group used the traditional Magnetic North parameters.

Both the pre-test and post-test required the subjects to calculate the wind correction angle (WCA), the ground speed (GS), and the estimated time enroute (ETE), from the winds aloft, the aircraft true airspeed (TAS), and the enroute course and distance. The post-test additionally measured the calculation of magnetic heading (MH) for the control group and the calculation of true flight track (TFT) for the experimental group. It is important to note that the TFT and the MH are the primary course guidance parameters used for navigation for their respective navigation models (i.e. Geographic North versus Magnetic North). Therefore this measurement is the measure of accuracy that primarily reflects the impact of two different models on the performance of each group. The calculations done by the experimental group to compute TFT are similar to the calculations done by the control group to compute MH with the exception that there are fewer steps to find TFT versus finding $M H$.

The accuracy of the subjects' answers was measured by comparing their answers to the correct responses and the difference recorded as a numerical error value. For each answer on the post-test, the students were given the same error margin that was allowed in the pretest for WCA, GS, ETE before an error value was assigned. As was done in the pre-test, the duration of time for each subject to accomplish the problem was noted and recorded to the nearest minute.

\section{ANAL YTICAL PLAN}

The objective of this study was to compare the performance of the two different groups. This study compares the performance by considering the accuracy and the expediency of performing the navigational tasks. A great deal of emphasis was placed on determining the homogeneity of the two subject groups and the consistency of the two different instructional lesson plans.

Thus, the first step was to analyze the pre-study survey and the pre-test to establish a relationship within and between the two study groups and between the two instructional presentations. A combination of two-tail t tests and Chi-square tests with alphas of .05 was used for this analysis.

The second step concentrated on the main objective of comparing the performance of the two groups by evaluating: the accuracy of the computations performed by the subjects and the amount of time they needed to accomplish the task.

The accuracy of the subjects' computations on the pre- and post-tests was expected to vary in either a positive or negative direction from the correct answer. But, for the pre and posttest problems, the data collected to measure the accuracy of calculating ground peed (GS) and wind correction angle (WCA) did not adequately measure the degree or amount of error, but only if an error was made. Therefore, the amount of error measured did not proportionally reflect the level of knowledge or skill of the subject, but only the nominal scale value of whether the subject did or did not make an error. Therefore, a chisquare test was used for this data.

The time to accomplish the task provided ratio scale data and a two-tail $t$ test with an alpha of .05 was used to analyze the data.

\section{RESEARCH OUTCOMES}

The post-test data collected in the study was evaluated to determine if the Geographic North Model used by the experimental group had a significant effect on their performance of navigational tasks when compared to the control group's performance of similar navigation tasks.

\section{Navigation Post-test}

The navigational post-test consisted of two parts: (a) performing navigation tasks for two legs of a crosscountry flight and (b) performing a navigation task for an emergency deviation to the nearest airport while en route. The post-test was conducted at the completion of the instruction for both the experimental and the control groups.

\section{Cross Country Problem}

The data (Table 5) from the cross-country portion of the post-test was analyzed to determine if the there was a significant difference between the two sample groups which was considered to be a result of the treatment given rather than by chance. The comparison of the performance outcomes between the two groups was measured using the: accuracy of problem solutions and the duration of time required to accomplish the task. 
TABLE 5

POSTTEST CHARTS (CROSS COUNTRY)

\begin{tabular}{|c|c|c|c|c|c|}
\hline Subject & & GS* Error & WCA* Error & TFT* Error & Time in Min. \\
\hline \multicolumn{6}{|c|}{ Experimental Group } \\
\hline 1 & & No & No & No & 4 \\
\hline 2 & & No & No & No & 4 \\
\hline 3 & & Yes & Yes & No & $s$ \\
\hline 4 & ' & No & No & No & 4 \\
\hline 5 & & No & No & No & 3 \\
\hline 6 & & Yes. & Yes & No & 6 \\
\hline 7 & & No & No & No & 5 \\
\hline 8 & & No & No & No & 3 \\
\hline 9 & & No & Yes & No & 5 \\
\hline 10 & & No & No & No & 8 \\
\hline 11 & & No & No & No & 4 \\
\hline Stmitric & & 2 Errors = $18 \%$ & 3 Errors - $27 \%$ & 0 Erors $-0 \%$ & \\
\hline $\mathbf{N}$ & & 11 & 11 & 11 & 11 \\
\hline 8 & & NA & NA & NA & 4.64 \\
\hline $\mathbf{E x}$ & & NA & NA & NA & 51 \\
\hline$\Sigma x^{2}$ & & NA & NA & NA & 257 \\
\hline s & & NA & NA & NA & 1.43 \\
\hline$s^{2}$ & & NA & $\mathbf{N A}$ & NA & 2.5 \\
\hline \multicolumn{6}{|l|}{ Control Cromen } \\
\hline 1 & & No & No & Yes & 9 \\
\hline 2 & & No & No & No & 4 \\
\hline 3 & & No & No & No & 6 \\
\hline 4 & & No & No & No & 6 \\
\hline 5 & & No & No & $Y=s$ & 8 \\
\hline 6 & & No & No & No & 6 \\
\hline 7 & & No & No & Yes & $s$ \\
\hline 8 & & No & No & No & 3 \\
\hline 9 & & No & No & No & 4 \\
\hline 10 & & No & No & No & 5 \\
\hline Smatistic & & 0 Eтrors $=0 \%$ & 0 Errors $=0 \%$ & 3 Estors $=30 \%$ & \\
\hline$N$ & & 10 & 10 & 10 & 10 \\
\hline $\bar{x}$ & & NA & NA & NA & 5.80 \\
\hline$\Sigma x$ & & NA & NA & NA & 58 \\
\hline$\Sigma \mathbf{X}^{2}$ & & NA & NA & NA & 360 \\
\hline s & & NA & NA & NA & 1.62 \\
\hline$s^{2}$ & & NA & NA & NA & 2.62 \\
\hline
\end{tabular}

Note: *GS = Ground Speed; *WCA $=$ Wind Correction Angle; *TFT = True Flight Track; ${ }^{*} \mathrm{MH}=$ Magnetic Heading. 
Accuracy Data. The data collected for the errors of calculating GS, WCA, MH, and TFT did not adequately measure the degree or amount of error, but only if an error was made. Therefore, the amount of error measured did not proportionally reflect the level of knowledge or skill of the subject. Since the GS error and the WCA error were measured identically for both study groups and, therefore, were not dependent on the independent variable of the navigation model type (that is, Geographic North or Magnetic North based), this data was not used to evaluate the hypothesis. The TFT and MH are different variables for the experimental and control groups, are dependent on the model type, and are analyzed for outcomes.

The nominal scale values of the TFT and MH error data were non-parametric and the statistic of Chi Square was used to analyze this data where:

Ho: the errors are independent of the study population

$\mathrm{H1}$ : the errors are related to the study population

The resulting calculation for the post-test data indicating the subjects' errors committed for TFT and MH computations is:

$\mathrm{X}$ observed $=|3.55|<\mathrm{X}$ critical $(.05,1)=3.8415$
The null hypothesis was not rejected and the errors made were independent of the study groups. Therefore, the two groups were considered as being from the same population.

Duration-of-Time-Data. The data collected for the duration of time required to complete the task were ratio scale parametric values and the statistic of a "two-tail" $t$ Test was used to analyze this data where:

Ho: $\mathrm{u} 1-\mathrm{u} 2=0$ (the difference between the sample groups is not significant)

Ha: $\mathrm{ul}-\mathrm{w} 2>0$ (the difference between the sample groups is significant)

The resulting calculation is:

2.093

tx1-X2 observed $=1.74<t$ critical $(.05,19)=$

Thus the null hypothesis was not rejected, the difference between the sample groups was not significant.

\section{Emergency Problem}

The data (Table 6) from the emergency portion of the posttest were analyzed in a similar fashion as was done for the cross-country portion. The same parameters and methods of analysis applied. 
TABLE 6

POSTTEST CHARTS (EMERGENCY)

\begin{tabular}{|c|c|c|c|c|c|}
\hline Subject & & GS* Error & WCA* Error & IFT* Error & Time in Min. \\
\hline \multicolumn{6}{|c|}{ Experimentil Grousp } \\
\hline 1 & & No & No & No & 4 \\
\hline 2 & & No & No & No & 3 \\
\hline 3 & & No & Yes & No & 8 \\
\hline 4 & & No & No & No & 4 \\
\hline 5 & ' & - & - & - & - \\
\hline 6 & & Yes & Yes & Yes & 5 \\
\hline 7 & & Yes & Yes & Yes & 3 \\
\hline 8 & & No & No & No & 4 \\
\hline 9 & & No & No & No & 4 \\
\hline 10 & & No & No & No & 2 \\
\hline 11 & & - & - & - & - \\
\hline Strtistic & & 2 Erros $-22 \%$ & 3 Errors $=33 \%$ & 2 Errors $=22 \%$ & \\
\hline $\mathbf{N}$ & & 9 & 9 & 9 & 9 \\
\hline$\overline{\mathbf{x}}$ & & NA & $\mathbf{N A}$ & NA & 4.11 \\
\hline$\Sigma x$ & & NA & NA & NA & 37 \\
\hline $2 x^{2}$ & & NA & NA & NA & 175 \\
\hline s & & NA & NA & NA & 1.69 \\
\hline$s^{2}$ & & NA & NA & NA & 286 \\
\hline \multicolumn{6}{|l|}{ Control Group } \\
\hline 1 & & No & No & Yes & 6 \\
\hline 2 & & No & No & No & 5 \\
\hline 3 & & No & No & No & 6 \\
\hline 4 & & No & No & Yes & 5 \\
\hline 3 & & No & No & Yes & s \\
\hline 6 & & No & No & No & 6 \\
\hline 7 & & No & Yes & Yes & 6 \\
\hline 8 & & No & No & No & 7 \\
\hline 9 & & No & No & No & 7 \\
\hline 10 & & - & - & - & - \\
\hline Stminte & & 0 Errors $=0 \%$ & 1 Error $=11 \%$ & 4 Errors $=44 \%$ & \\
\hline N & & 9 & 9 & 9 & 9 \\
\hline $\bar{x}$ & & NA & NA & NA & 5.89 \\
\hline$\Sigma x$ & & NA & NA & NA & 53 \\
\hline$\Sigma x^{2}$ & & NA & NA & NA & 317 \\
\hline$s$ & & NA & NA & NA & .78 \\
\hline $\mathrm{s}^{2}$ & & NA & NA & NA & .61 \\
\hline
\end{tabular}

Note: "GS = Ground Speed; "WCA = Wind Correction Angle; "MH = Magnetic Heading; ${ }^{*}$ TFT $=$ True Flight Track. 


\section{Accuracy Data.}

The nominal scale values of the TFT and MH error data were non-parametric and the statistic of Chi Square was used to analyze this data where:

Ho: the errors are independent of the study population

$\mathrm{Hl}$ : the errors are related to the study population

The resulting calculation for the Post-test data indicating the subjects' errors committed for TFT and MH computations is:

$$
X \text { observed }=|1.00|<X \text { critical }(.05,1)=3.8415
$$

The null hypothesis was not rejected and the errors made were independent of the study groups. Therefore, the two groups were considered as being from the same population.

Duration-of-Time-Data. Similar to the cross country scenario, the emergency duration-of-time to complete the task data were ratio scale parametric values and the statistic of a "two-tail" $t$ test was used to analyze this data where:

Ho: $\mathbf{u l}-\mathrm{u} 2=0$ (the difference between the sample groups is not significant)

Ha: $\mathrm{u} 1-\mathrm{u} 2>0$ (the difference between the sample groups is significant)

The resulting calculation is:

tx1-X2 observed $=4.61>t$ critical $(.05,16)=$ 2.093

Thus the null hypothesis was not rejected, the difference between the sample groups was significant.

\section{Post-test Analysis}

Cross-country problem. The accuracy of performing the navigation task for the cross-country problem was measured for the calculation of the wind correction angle (WCA) and ground speed (GS) for both the experimental and control groups. The procedures and computations required to reach these solutions (WCA and GS) were exactly the same for both the experimental group and the control group and, therefore, were not dependent on the independent variable of the navigation model type (that is, Geographic North or Magnetic North based).
Therefore, this data was not used to evaluate the hypothesis.

The accuracy of performing the navigation task for the cross-country problem was also measured for the calculation of the true flight track (TFT) for the experimental group and magnetic heading (MH) for the control group. TFT was the basic guidance parameter used by the Geographic North Model and MH was the basic guidance parameter used by the Magnetic North Model. The procedures and computations required to reach these solutions (TFT and MH) were different and dependent upon the model they represented. Therefore the accuracy of the TFT and MH calculations for the experimental group and control group, respectively, were analyzed to test the hypothesis.

A Chi-square (alpha $=.05$ ) performed on error data collected (Table 5) did not show a significant difference between the two groups and did not support the hypothesis that the experimental group performed more accurately than the control group.

The duration-of-time data required to perform the cross-country navigation task was measured for both the experimental group and the control group. The data collected (Table 5) shows that the duration-of-time to accomplish the task was an average of 4.64 minutes for the experimental group and 5.80 minutes for the control group -- a difference of 1.16 minutes. A $t$ test (alpha $=.05$ ) performed on this data did not show an adequate significant difference between the two groups to support the hypothesis that the experimental group performed the task more expeditiously than the control group.

Emergency Problem. Based on the same rationale as set forth in the previous discussion for the cross-country problem, the data for WCA and GS was not used in the emergency problem to evaluate the hypothesis.

Likewise, based on the same rationale as set forth in the previous discussion for the cross-country problem, the experimental problem data regarding the accuracy of the TFT and MH calculations for the experimental group and control group, respectively, were analyzed to test the hypothesis.

A Chi-square (alpha $=.05$ ) performed on the error data collected (Table 6) did not show a significant difference between the two groups and did not support the hypothesis that the experimental group performed more accurately than the control group.

The duration-of-time data required to perform the cross-country navigation task was measured for both the 
experimental group and the control group. The data collected (Table 6) showed that the duration of time to accomplish the task was an average of 4.11 minutes for the experimental group and 5.89 minutes for the control group - a difference of 1.78 minutes. A $t$ test (alpha $=.05$ ) performed on this data did show a significant difference between the two groups and did support the hypothesis that the experimental group performed the task more expeditiously than the control group.

\section{RESEARCH CONCLUSIONS}

This study can substantiate a conclusion that the experimental group performed the navigation task more expeditiously than the control group in the Emergency problem. However, this researcher is cautious in this conclusion because only one of the two navigation tasks showed a significant difference between the duration-oftime to perform the navigation task. The researcher is encouraged from the results to continue research into the benefits of a Geographic North Navigation Model.

In general, the study proceeded as planned, but the findings were not as robust as hoped. Many revelations about this study were seen while it was being conducted. Perhaps the best outcome of the study is the encouragement to do further research into the benefits of changing the current Magnetic North based navigation model to one based on geographic north.

\section{Recommendations for Future Study}

This research has laid the foundation for further study into the impact of changing the basic paradigm of aviation navigation to a Geographic North Model rather than the currently used Magnetic North Model. In addition, the rapid expansion of technology in aviation demands similar research in the human/technology/machine interface, which in turn demands new and creative approaches to aviation operations.

Specific research should involve the continued study of the advantages of the Geographic North Navigation Model utilizing Personal Computer Aviation Training Devices (PCATDs) to compare the performance of subjects using the Geographic North Model versus the Magnetic North Model during flight scenarios.

Dr. Michael Larson is an assistant professor and flight training coordinator at the University of Nebraska at Omaha Aviation Institute. He holds a Bachelor of Education from Nebraska Wesleyan University and a Master of Science and Doctor of Education from Oklahoma State University. Dr. Larson's flying experience includes: pilot for the Nebraska Department of Aeronautics; Air Ambulance operations; Part 121 operations for Pan American World Airways in Berlin, Germany; Part 135 bush flying in Alaska; over 2000 hours of flight instructing; and FAA Designated examiner in Alaska and Oklahoma. His educational experience includes: high school mathematics and physics teacher, community college ground school instructor, pilot refresher course and aerospace education coordinator for the Nebraska Department of Aeronautics, adjunct professor of aviation studies at Oklahoma State University, and many presentations on aerodynamics of airplanes and boomerangs to various seminars and symposiums nationwide. 


\section{REFERENCES}

Aviation instructor's handbook. (1977). Washington, DC: Federal Aviation Administration, Flight Standards Service.

Bowditch, N. (1977). American practical navigator. Washington, DC: Defense Mapping Agency_Hydrographic Center.

Capstone Program. (2000). [On-Line, last updated June 26, 2000]. (Http//www.alaska. faa.gov/capstone/capstone.htm.), Anchorage, AK: Capstone Program.

Salkind, Neil J. (1997). Exploring Research, Third Edition. Upper Saddle River, NJ: Prentice Hall, Inc.

Federal Aviation Administration satellite navigation program master plan. (1993). Washington, DC: Research and Development Service, Satellite Program Office, Federal Aviation Administration.

Federal Aviation Regulations and Aeronautical Information Manual. (2001). Washington, DC: Flight Standards Service, Federal Aviation Administration.

Federal Radionavigation Plan. (1999). Springfield, VA: Document number DOT-VNTSC-RSPS-98-1/DOD-4650.5, National Technical Information Service.

Flight Training Handbook. (1980). Washington, DC: Flight Standards Service, Federal Aviation Administration.

GPS fluctuations over time on May 2, 2000. (2000). [On-Line, last updated June 15, 2000]. (http//www.igeb.gov/sa/diagram.shtml). Washington, DC: NOAA National Geodetic Survey.

Nolan, M. (1994). Fundamentals of air traffic control. Belmont, CA: Wadsworth Publishing Company.

Private pilot practical test standards. (1997). Washington, DC: Office of Flight Operations, Federal Aviation Administration.

Private pilot manual. (1997). Englewood, CO: Jeppesen Sanderson, Inc.

The global positioning system: A shared national asset: Recommendations for technical improvements and enhancements. (1995). Washington, DC: National Research Council, Committee on the Future of the Global Positioning System. National Academy Press.

Williams, K. W. (1999). GPS user-interface design problems. Springfield, VA: National Technical Information Service. 